\title{
Deposição de proteína e gordura nos cortes nobres de frangos alimentados com farinha de resíduos da indústria de filetagem de tilápia
}

\section{Protein and fat deposition on noble cuts of broilers fed with tilapia industrial filleting waste}

\author{
Cinthia Eyng ${ }^{1}$; Ricardo Vianna Nunes²; Alice Eiko Murakami \\ Paulo Cesar Pozza ${ }^{3}$; Carina Scherer ${ }^{4 *}$; \\ Wagner Tiago Mozer da Silva'; Luis Daniel Giusti Bruno ${ }^{2}$
}

\section{Resumo}

Este estudo teve por objetivo avaliar o efeito do fornecimento de diferentes níveis de farinha de resíduos da indústria de filetagem de tilápia (FT) sobre a taxa de deposição de proteína (TDP) e gordura (TDG) no peito e nas pernas (coxa e sobrecoxa) de frangos de corte, abatidos aos 42 dias de idade. Foram utilizados 480 pintos de um dia, da linhagem Cobb, distribuídos em um delineamento experimental inteiramente casualizado, com cinco tratamentos, seis repetições e 16 aves por unidade experimental. Os tratamentos experimentais consistiram em cinco níveis $(0,2,4,6$ e 8\%) de inclusão da FT. As dietas experimentais foram isoenergéticas e isonutritivas, seguindo as recomendações de exigências nutricionais dos frangos de corte para as fases de 1 a 21 e 22 a 42 dias de idade. Não houve influência $(\mathrm{P}>0,05)$ dos níveis de inclusão da FT sobre a TDP e TDG no peito e nas pernas (coxa e sobrecoxa) das aves. De acordo com os resultados encontrados constatou-se que pode-se incluir até $8 \%$ de farinha de resíduos da indústria de filetagem de tilápia sem prejuízo nos parâmetros de deposição de gordura e proteína na carcaça de frangos de corte.

Palavras-chave: Alimentos alternativos, composição química da carcaça, farinha de peixe

\begin{abstract}
The present research was aimed to evaluate the effect of different inclusion levels of tilapia industrial filleting waste (TM) on protein (PDR) and fat deposition rate (FDR) in broilers chicken breast and legs (thigh and drumstick), slaughtered at 42 days of age. Four hundred and eighty chickens were used in a completely randomized design with five treatments, six replicates and sixteen birds per experimental unit. The treatments consisted in five inclusion levels $(0,2,4,6$ and $8 \%)$ of TM. The experimental diets were isocaloric and isonutritives, following the nutritional requirements recommendations for stages 1 to 21 and 22 to 42 days old for broilers chickens. No influence $(\mathrm{P}>0.05)$ for inclusion levels of TM on PDR and FDR in the poultries breast and legs (thighs and drumsticks). According to the results, the inclusion of $8 \%$ of tilapia industrial filleting waste in broiler feeding did not affect the parameters of protein and fat deposition rate in broilers chicken carcass.
\end{abstract}

Key words: Alternative feedstuffs, chemical carcass composition, fish meal

1 Dra em Zootecnia, Universidade Estadual de Maringá, UEM, Maringá, PR. E-mail: cinthiaeyng@hotmail.com

2 Profs. da Universidade Estadual do Oeste do Paraná, UNIOESTE, Marechal Cândido Rondon, PR. E-mail: nunesrv@hotmail. com; ldgbruno@gmail.com

3 Profs.da UEM, Maringá, PR. E-mail: aemurakami@uem.br; pcpozza@yahoo.com.br

4 Pós-Doutorado, UNIOESTE, Marechal Cândido Rondon, PR. E-mail: carina_scherer@hotmail.com

5 M.e. em Zootecnia, UNIOESTE, Marechal Cândido Rondon, PR. E-mail: wtmozer@gmail.com

* Autor para correspondência 


\section{Introdução}

No Brasil, a avicultura é uma das atividades mais avançadas tecnologicamente, principalmente a de corte, com níveis de produtividade similares a países mais desenvolvidos (NOVELLO et al., 2008). No entanto, para dar suporte a este avanço, os custos de produção devem ser os mais baixos possíveis, e, de acordo com Silva et al. (2006), dentre os principais gastos, a nutrição tem representado a maior parcela.

Desta forma, à medida que os custos de produção aumentam, os nutricionistas têm a necessidade de buscar novas alternativas, tendo a utilização de subprodutos da agroindústria como uma ferramenta interessante sob o ponto de vista econômico na produção animal (TUCCI et al., 2003).

A literatura apresenta alguns ingredientes alternativos com possibilidade de compor as dietas para animais, e, segundo Ponce e Gernat (2002) a indústria da tilápia tem crescido significativamente e os resíduos gerados por ela se devem ao fato de que somente o filé é removido para o consumo humano. Essa porção constitui aproximadamente $36 \%$ de todo o peixe, restando $64 \%$ de resíduo das diversas operações de processamento, resultando assim na farinha de resíduo de filetagem de tilápia.

Além de ser uma fonte de renda alternativa para as indústrias processadoras de peixes, a utilização dos subprodutos nas rações animais contribui para a proteção ambiental. Entretanto, as matériasprimas utilizadas e as condições de processamento como temperatura e pressão utilizada são fatores que podem afetar a qualidade da farinha (WANG; PARSONS, 1998).

Apesar do conhecimento sobre as variações no valor nutricional desses subprodutos, trabalhos avaliando os efeitos da utilização desses resíduos nas dietas sobre o desempenho e consequentemente na deposição de gordura e proteína são escassos. Segundo Moreira et al. (2003) a produção de frangos de corte adotou alguns critérios com relação à qualidade da carcaça, sendo que a importância dessas características varia de acordo com a empresa, o tipo de produto comercializado e o mercado ao qual o produto se destina.

Além disso, a gordura excessiva tem sido reconhecida como um dos principais problemas da indústria da carne de frango atual, cujo excesso não reduz apenas o rendimento de carcaça e a eficiência alimentar das aves, mas também a aceitação do consumidor, já que o mercado hoje exige uma carne mais magra (GAYA et al., 2006).

Este estudo teve por objetivo avaliar o efeito do fornecimento de diferentes níveis de farinha de resíduos da indústria de filetagem de tilápia sobre a taxa de deposição de proteína e gordura no peito e nas pernas (coxa e sobrecoxa) de frangos de corte.

\section{Material e Métodos}

Foram utilizados 480 pintos de corte com um dia de idade, da linhagem Cobb e peso médio de 43,87 $\mathrm{g}$, distribuídos de acordo com um delineamento inteiramente ao acaso, com cinco tratamentos, seis repetições e 16 aves por unidade experimental.

Os tratamentos experimentais consistiram de cinco níveis de inclusão $(0,2,4,6$ e 8\%) da farinha de resíduo da indústria de filetagem de tilápia (FT), contendo $3.733 \mathrm{kcal} / \mathrm{kg}$ de energia metabolizável aparente e $45,25 \%$ de proteína bruta. Os dados de composição química, os valores de energia metabolizável aparente, aparente corrigida para o balanço de nitrogênio, os coeficientes de digestibilidade dos aminoácidos e os aminoácidos digestíveis verdadeiros da farinha de resíduos da indústria de filetagem de tilápia em estudo foram publicados por Eyng et al. (2009).

As dietas experimentais (Tabelas 1 e 2 ) foram isoenergéticas e isonutritivas, segundo as recomendações propostas por Rostagno et al. (2005) para frangos de corte, nas fases de 1 a 21 e de 22 a 42 dias de idade. Durante todo o experimento as aves receberam água e ração ad libitum. 
Tabela 1. Composição das dietas experimentais utilizadas nas fases de 1 a 21 dias de idade.

\begin{tabular}{|c|c|c|c|c|c|}
\hline \multirow{2}{*}{ Ingredientes } & \multicolumn{5}{|c|}{ Inclusão de Farinha de Tilápia (\%) } \\
\hline & 0 & 2 & 4 & 6 & 8 \\
\hline Milho & 55,42 & 57,03 & 58,65 & 60,26 & 61,87 \\
\hline Farelo de Soja & 37,04 & 34,69 & 32,34 & 29,99 & 27,64 \\
\hline Óleo de Soja & 2,96 & 2,24 & 1,52 & 0,79 & 0,07 \\
\hline Fosfato Bicálcico & 1,85 & 1,46 & 1,06 & 0,66 & 0,26 \\
\hline Calcário Calcítico & 0,91 & 0,77 & 0,64 & 0,5 & 0,37 \\
\hline Sal comum & 0,50 & 0,48 & 0,47 & 0,45 & 0,43 \\
\hline DL-Metionina 99\% & 0,32 & 0,31 & 0,31 & 0,31 & 0,31 \\
\hline L-Lisina HCL & 0,30 & 0,31 & 0,32 & 0,33 & 0,34 \\
\hline L-Treonina & 0,12 & 0,12 & 0,12 & 0,12 & 0,12 \\
\hline Antioxidante $^{1}$ & 0,01 & 0,01 & 0,01 & 0,01 & 0,01 \\
\hline Anticoccidiano $^{2}$ & 0,05 & 0,05 & 0,05 & 0,05 & 0,05 \\
\hline Suplemento Mineral ${ }^{3}$ & 0,05 & 0,05 & 0,05 & 0,05 & 0,05 \\
\hline Suplemento Vitamínico ${ }^{4}$ & 0,10 & 0,10 & 0,10 & 0,10 & 0,10 \\
\hline Cloreto de Colina $60 \%$ & 0,06 & 0,06 & 0,06 & 0,06 & 0,06 \\
\hline Promotor de crescimento ${ }^{5}$ & 0,01 & 0,01 & 0,01 & 0,01 & 0,01 \\
\hline Inerte & 0,30 & 0,30 & 0,30 & 0,30 & 0,30 \\
\hline Farinha de Tilápia & 0,00 & 2,00 & 4,00 & 6,00 & 8,00 \\
\hline \multicolumn{6}{|l|}{ Composição Nutricional (calculada) } \\
\hline Energia Metabolizável $(\mathrm{kcal} / \mathrm{kg})$ & 3.002 & 3.002 & 3.002 & 3.002 & 3.002 \\
\hline Proteína Bruta (\%) & 21,99 & 21,99 & 21,99 & 21,99 & 21,99 \\
\hline Cálcio $(\%)$ & 0,908 & 0,908 & 0,908 & 0,908 & 0,908 \\
\hline Fósforo Disponível (\%) & 0,454 & 0,454 & 0,454 & 0,454 & 0,454 \\
\hline Lisina Digestível (\%) & 1,276 & 1,276 & 1,276 & 1,276 & 1,276 \\
\hline Metionina Digestível (\%) & 0,605 & 0,612 & 0,619 & 0,627 & 0,634 \\
\hline Metionina + Cistina Digestível (\%) & 0,907 & 0,907 & 0,906 & 0,906 & 0,907 \\
\hline Triptofano Digestível (\%) & 0,240 & 0,236 & 0,232 & 0,227 & 0,223 \\
\hline Treonina Digestível (\%) & 0,829 & 0,829 & 0,829 & 0,829 & 0,829 \\
\hline Potássio (\%) & 0,834 & 0,805 & 0,778 & 0,748 & 0,719 \\
\hline Sódio $(\%)$ & 0,218 & 0,218 & 0,218 & 0,218 & 0,218 \\
\hline
\end{tabular}

${ }^{1}$ BHT (butil-hidroxi-tolueno); ${ }^{2}$ Salinomicina, 12\%; ${ }^{3}$ Suplemento mineral, conteúdo: magnésio - 16,0 g; ferro - 100,00 g; zinco - 100,0 g; cobre - 2,0 g; cobalto - 2,0 g; iodo - 2,0 g; e veículo q.s.p. - $1.000 \mathrm{~g} ;{ }^{4}$ Suplemento vitamínico, conteúdo: vit. A 10.000.000 UI; vit. D3 - 2.000.000 UI; vit. E - 30.000 UI; vit. B1 - 2,0 g; vit. B6 - 4,0 g; ácido pantotênico - 12,0 g; biotina - 0,10 g; vit. K3 - 3,0 g; ácido fólico - 1,0 g; ácido nicotínico - 50,0 g; vit. B12 - 15.000 mcg; selênio - 0,25 g; e veículo q.s.p. - 1.000 g; ${ }^{5}$ Avilamicina $10 \%$.

Fonte: Elaboração dos autores. 
Tabela 2. Composição das dietas experimentais utilizadas nas fases de 22 a 42 dias de idade.

\begin{tabular}{|c|c|c|c|c|c|}
\hline \multirow{2}{*}{ Ingredientes } & \multicolumn{5}{|c|}{ Inclusão de Farinha de Tilápia (\%) } \\
\hline & 0 & 2 & 4 & 6 & 8 \\
\hline Milho & 62,93 & 64,54 & 66,15 & 67,77 & 69,38 \\
\hline Farelo de Soja & 29,09 & 26,74 & 24,39 & 22,04 & 19,69 \\
\hline Óleo de Soja & 3,88 & 3,16 & 2,44 & 1,71 & 0,99 \\
\hline Fosfato Bicálcico & 1,62 & 1,22 & 0,82 & 0,42 & 0,02 \\
\hline Calcário Calcítico & 0,83 & 0,70 & 0,56 & 0,43 & 0,30 \\
\hline Sal comum & 0,46 & 0,44 & 0,43 & 0,41 & 0,39 \\
\hline DL-Metionina 99\% & 0,24 & 0,24 & 0,24 & 0,24 & 0,24 \\
\hline L-Lisina HCL & 0,27 & 0,28 & 0,29 & 0,30 & 0,31 \\
\hline L-Treonina & 0,09 & 0,09 & 0,09 & 0,09 & 0,09 \\
\hline Antioxidante $^{1}$ & 0,01 & 0,01 & 0,01 & 0,01 & 0,01 \\
\hline Anticoccidiano $^{2}$ & 0,05 & 0,05 & 0,05 & 0,05 & 0,05 \\
\hline Suplemento Mineral ${ }^{3}$ & 0,05 & 0,05 & 0,05 & 0,05 & 0,05 \\
\hline Suplemento Vitamínico ${ }^{4}$ & 0,10 & 0,10 & 0,10 & 0,10 & 0,10 \\
\hline Cloreto de Colina $60 \%$ & 0,06 & 0,06 & 0,06 & 0,06 & 0,06 \\
\hline Promotor de crescimento ${ }^{5}$ & 0,01 & 0,01 & 0,01 & 0,01 & 0,01 \\
\hline Inerte & 0,30 & 0,30 & 0,30 & 0,30 & 0,30 \\
\hline Farinha de Tilápia & 0,00 & 2,00 & 4,00 & 6,00 & 8,00 \\
\hline \multicolumn{6}{|l|}{ Composição Nutricional (calculada) } \\
\hline Energia Metabolizável $(\mathrm{kcal} / \mathrm{kg})$ & 3.151 & 3.151 & 3.151 & 3.151 & 3.151 \\
\hline Proteína Bruta (\%) & 18,99 & 18,99 & 18,99 & 18,99 & 18,99 \\
\hline Cálcio $(\%)$ & 0,805 & 0,805 & 0,805 & 0,805 & 0,805 \\
\hline Fósforo Disponível (\%) & 0,402 & 0,402 & 0,402 & 0,402 & 0,402 \\
\hline Lisina Digestível (\%) & 1,073 & 1,073 & 1,073 & 1,073 & 1,073 \\
\hline Metionina Digestível (\%) & 0,503 & 0,510 & 0,517 & 0,524 & 0,531 \\
\hline Metionina + Cistina Digestível (\%) & 0,772 & 0,772 & 0,772 & 0,772 & 0,772 \\
\hline Triptofano Digestível (\%) & 0,201 & 0,197 & 0,192 & 0,188 & 0,184 \\
\hline Treonina Digestível (\%) & 0,697 & 0,697 & 0,697 & 0,697 & 0,697 \\
\hline Potássio (\%) & 0,709 & 0,681 & 0,652 & 0,623 & 0,595 \\
\hline Sódio (\%) & 0,202 & 0,202 & 0,202 & 0,202 & 0,202 \\
\hline
\end{tabular}

${ }^{1}$ BHT (butil-hidroxi-tolueno); ${ }^{2}$ Salinomicina, 12\%; ${ }^{3}$ Suplemento mineral, conteúdo: magnésio - 16,0 g; ferro - 100,00 g; zinco - 100,0 g; cobre - 2,0 g; cobalto - 2,0 g; iodo - 2,0 g; e veículo q.s.p. - $1.000 \mathrm{~g} ;{ }^{4}$ Suplemento vitamínico, conteúdo: vit. A 10.000.000 UI; vit. D3 - 2.000.000 UI; vit. E - 30.000 UI; vit. B1 - 2,0 g; vit. B6 - 4,0 g; ácido pantotênico - 12,0 g; biotina - 0,10 $\mathrm{g}$; vit. K3 - 3,0 g; ácido fólico - 1,0 g; ácido nicotínico - 50,0 g; vit. B12 - 15.000 mcg; selênio - 0,25 g; e veículo q.s.p. - 1.000 g; ${ }^{5}$ Avilamicina $10 \%$.

Fonte: Elaboração dos autores.

Para o cálculo da taxa de deposição de proteína (TDP) e taxa de deposição de gordura (TDG) no peito e nas pernas (coxa e sobrecoxa) dos frangos de corte, ao final do período experimental, foi retirada uma amostra de 2 aves por unidade experimental, totalizando 12 aves por tratamento, representando o peso médio de cada parcela $( \pm 10 \%)$. As aves selecionadas foram submetidas à um jejum por um período de 12 horas, sendo posteriormente abatidas por meio de ruptura da veia jugular. Após sangradas e depenadas as aves foram evisceradas e posteriormente realizou-se os cortes, utilizando peito e pernas (coxa e sobrecoxa) sem pele, que foram congelados em sacos plásticos e posteriormente moídos em moinho de carne industrial. Os cortes moídos foram pesados, homogeneizados e levados à estufa de ventilação forçada a $55^{\circ} \mathrm{C}$ por 72 horas, para a realização da pré-secagem. Em seguida 
foram moídos em moinho tipo bola e conduzidos ao laboratório para realização das análises químicas. Foram determinadas a matéria seca, proteína bruta e extrato etéreo dos cortes, conforme metodologia descrita por Silva e Queiroz (2002).

As taxas de deposição de proteína e gordura foram calculadas por meio de abate feito a partir de um grupo adicional de 6 pintinhos com 1 dia de idade, comparadas com aquelas aves abatidas ao término do período experimental.

A TDP e TDG foram calculadas segundo fórmulas citadas por Scherer et al. (2011):

$$
\mathrm{TDP}=\left(\mathrm{QP}_{\mathrm{cf}}-\mathrm{QP}_{\mathrm{ci}}\right) / \mathrm{PE},
$$

em que, $\mathrm{QP}_{\mathrm{cf}}$ é a quantidade, em gramas, de proteína nos cortes finais; $\mathrm{QP}_{\mathrm{ci}}$ é a quantidade de proteína nos cortes iniciais e, PE é o período experimental em dias. $\mathrm{AQP}_{\mathrm{cf}}$ foi obtida multiplicando-se o peso médio dos cortes das aves de uma unidade experimental, ao final do experimento, pela respectiva proteína bruta dos cortes (PBC); enquanto $\mathrm{QP}_{\mathrm{ci}}$ foi obtida pelo peso médio das aves da respectiva unidade experimental, ao início do experimento, multiplicando pelo rendimento médio dos cortes e pela $\mathrm{PBC}$ média do grupo adicional (6 pintinhos abatidas inicialmente).

$$
\mathrm{TDG}=\left(\mathrm{QG}_{\mathrm{cf}}-\mathrm{QG}_{\mathrm{ci}}\right) / \mathrm{PE},
$$

em que, $\mathrm{QG}_{\mathrm{cf}}$ é a quantidade, em gramas, de gordura nos cortes finais; $\mathrm{QG}_{\mathrm{ci}}$ é a quantidade de gordura nos cortes iniciais e, PE é o período experimental em dias. $\mathrm{QG}_{\mathrm{cf}}$ e $\mathrm{QG}_{\mathrm{ci}}$ foram obtidas de modo similar as $\mathrm{QP}_{\mathrm{cf}}$ e $\mathrm{QP}_{\mathrm{ci}}$, utilizando-se os valores de extrato etéreo dos cortes ao invés de proteína bruta.

Como procedimento estatístico, os dados coletados foram submetidos à análise de variância por intermédio do programa Statistical Analysis System (SAS, 2001). A comparação de médias para os dados de deposição de proteína e gordura nos cortes de coxa/sobrecoxa e peito foi realizada pelo teste de Tukey ao nível de 5\% de probabilidade.

\section{Resultados e Discussão}

Não houve influência $(\mathrm{P}>0,05)$ dos níveis de inclusão da FT sobre a taxa de deposição de proteína (TDP) e taxa de deposição de gordura (TDG) no peito e nas pernas (coxa e sobrecoxa) dos frangos de corte (Tabela 3).

Tabela 3. Taxa de deposição de proteína (TDP) e taxa de deposição de gordura (TDG) no peito e pernas (coxa e sobrecoxa) de frangos de corte, aos 42 dias de idade em função de diferentes níveis de inclusão de farinha de resíduos da indústria de filetagem de tilápia (FT).

\begin{tabular}{ccccc}
\hline & \multicolumn{2}{c}{ TDP $(\mathrm{g} /$ dia) } & \multicolumn{2}{c}{ TDG (g/dia) } \\
\hline Níveis de inclusão da FT (\%) & Pernas & Peito & Pernas & Peito \\
\hline $0^{\text {ns }}$ & 1,10 & 3,45 & 0,59 & 1,17 \\
$2^{\text {ns }}$ & 1,00 & 3,69 & 0,61 & 1,21 \\
$4^{\text {ns }}$ & 0,99 & 3,46 & 0,52 & 1,19 \\
$6^{\text {ns }}$ & 1,03 & 3,41 & 0,63 & 1,01 \\
$8^{\text {ns }}$ & 1,06 & 3,74 & 0,57 & 1,28 \\
CV (\%) & 5,14 & 7,70 & 8,36 & 11,40 \\
\hline
\end{tabular}

ns $=$ não significativo ao nível de $5 \%$ de probabilidade pelo teste de Tukey.

Fonte: Elaboração dos autores. 
Avaliando a composição química da carne de frangos (peito e coxa/sobrecoxa) alimentados com rações contendo farinha de peixe ou aveia branca, Novello et al. (2007), não observaram valores significativamente diferentes na carne do peito de frango em relação à umidade, às cinzas, à proteína bruta (PB) e ao extrato etéreo (EE), no entanto, verificaram que as rações com $9 \%$ de farinha de peixe e $10 \%$ de aveia branca aumentaram a quantidade de gordura na coxa/sobre-coxa dos frangos.

De modo semelhante, Novello et al. (2008), concluíram que a inclusão de farinha de peixe e aveia-branca em rações à base de milho e farelo de soja, nos níveis 9 e 10\%, respectivamente, provoca acúmulo de gordura na coxa/sobrecoxa de frangos de corte, e que a inclusão de $9 \%$ de farinha de peixe em rações à base milho e farelo de soja ocasiona aumento nos níveis de ácidos graxos poliinsaturados da série $\omega-3$.

$\mathrm{O}$ fato de não ter sido observado efeito $(\mathrm{P}<0,05)$ dos níveis de inclusão de FT sobre os valores de deposição de gordura e proteína tanto para coxa e sobrecoxa quanto para peito, pode ter ocorrido devido à formulação das rações experimentais terem sido isoenergéticas e isonutritivas, o que proporcionou a ingestão diária equilibrada de energia metabolizável e proteína bruta pelas aves (Tabela 4).

Tabela 4. Ingestão diária de energia metabolizável (EM) e proteína bruta (PB) nos períodos de 1 a 21 e de 22 a 42 dias de idade.

\begin{tabular}{|c|c|c|c|c|c|}
\hline & \multicolumn{5}{|c|}{ Inclusão de Farinha de Tilápia (\%) } \\
\hline & 0 & 2 & 4 & 6 & 8 \\
\hline & \multicolumn{5}{|c|}{1 a 21 dias } \\
\hline Consumo total de ração $^{1}$ (g/ave) & 1150,29 & 1222,28 & 1189,70 & 1202,73 & 1192,25 \\
\hline Consumo diário de ração (g/ave/dia) & 54,776 & 58,204 & 56,652 & 57,273 & 56,774 \\
\hline Consumo diário de EM (kcal/ave/dia) & 1,644 & 1,747 & 1,701 & 1,719 & 1,704 \\
\hline \multirow[t]{2}{*}{ Consumo diário de PB (g/ave/dia) } & 12,045 & 12,799 & 12,458 & 12,594 & 12,485 \\
\hline & \multicolumn{5}{|c|}{22 a 42 dias } \\
\hline Consumo total de ração $^{1}$ (g/ave) & 3499,37 & 3573,67 & 3568,14 & 3574,91 & 3627,94 \\
\hline Consumo diário de ração (g/ave/dia) & 166,637 & 170,175 & 169,911 & 170,234 & 172,759 \\
\hline Consumo diário de EM (kcal/ave/dia) & 5,251 & 5,362 & 5,354 & 5,364 & 5,444 \\
\hline Consumo diário de PB (g/ave/dia) & 31,644 & 32,316 & 32,266 & 32,327 & 32,807 \\
\hline
\end{tabular}

${ }^{1}$ Conforme dados de desempenho apresentados por Eyng et al. (2010).

Existem vários fatores que afetam a síntese de proteína e consequentemente o crescimento muscular. Entre eles pode-se citar: nível dietético de aminoácidos e nível energético da ração. A carência ou desbalanceamento entre os nutrientes podem influenciar a síntese ou a degradação protéica de uma maneira indireta, porque podem afetar a liberação de hormônios como GH e insulina, entre outros (TON et al., 2011).
Oliveira Neto et al. (2000) utilizando milho e óleo de soja como fonte de energia, constataram aumento linear no teor de gordura da carcaça de frangos de corte, em função do aumento dos níveis energéticos da ração. De modo semelhante, Ton et al. (2011), avaliaram rações contendo níveis crescentes de energia metabolizável e não observaram efeito sobre a taxa de deposição de proteína, porém notaram aumento linear na taxa de deposição de gordura na carcaça de codornas de corte aos 35 dias de idade 
conforme aumentou o nível energético das rações. Entretanto, Scherer et al. (2011) utilizando óleo de soja, milho e glúten de milho 60 como fonte de energia, verificaram que diferentes níveis de energia metabolizável influenciaram a taxa de deposição de proteína (TDP) nos cortes de codornas de corte, aos 14 dias de idade, enquanto a taxa de deposição de gordura (TDG) não sofreu efeito significativo. Esses resultados indicam a influência da composição nutricional da dieta sobre a composição da carcaça das aves.

Outro fator que pode influenciar na deposição de gordura é o equilíbrio ideal dos aminoácidos, sendo que o excesso de proteína bruta ou sua baixa digestibilidade pode propiciar aumento na taxa de deposição de gordura. Assim, deve-se atender às exigências diárias dos aminoácidos das aves visando a máxima deposição protéica e, ao mesmo tempo, mínima deposição de gordura na carcaça (TRINDADE NETO et al., 2009).

Segundo Si et al. (2001) o teor de proteína bruta e de aminoácidos essenciais de uma dieta influencia a composição da carcaça de frangos. Alto teor de proteína bruta promove um aumento no teor de proteína e reduz o teor de gordura na carcaça, ao passo que frangos alimentados com dietas marginais em aminoácidos consumirão mais para alcançar seus requerimentos para ganho de peso. Entretanto, de acordo com Leeson (1995) a deposição de proteína é predeterminada pela genética da ave, havendo um limite de deposição diário, que não pode ser compensado pela dieta. Gonzales e Sartori (2002), afirmam que o aumento da proteína corporal ocorre até certo período do desenvolvimento das aves, e, com o aumento da idade, a deposição de proteína é menor do que a deposição de gordura.

De acordo com Cancherini et al. (2005), para maximizar o crescimento muscular, a dieta das aves precisa atender as exigências diárias de proteína, e, para minimizar a deposição de gordura, deve evitar a ingestão excessiva de energia em relação à necessidade para manutenção e crescimento.
Os resultados observados levam à conclusão de que a utilização de farinha de resíduo de filetagem de tilápia, contendo cerca de 45,23\% de PB e $4.778 \mathrm{kcal} / \mathrm{kg}$ de EB, pode ser utilizada na ração de frangos de corte até no nível de $8 \%$ de inclusão, sem influenciar os parâmetros de deposição de gordura e proteína na carcaça.

\section{Referências}

CANCHERINI, L. C.; JUNQUEIRA, O. M.; OLIVEIRA, M. C.; ANDREOTTI, M. O.; BARBOSA, M. J. B. Utilização de subprodutos de origem animal em dietas formuladas com base em proteína bruta e proteína ideal para frangos de corte de 22 a 42 dias de idade. Revista Brasileira de Zootecnia, Brasília, v. 34, n. 2, p. 535-540, 2005.

EYNG, C.; NUNES, R. V.; POZZA, P. C.; SILVA, W. T. M.; NAVARINI, F. C.; HENZ, J. R. Farinha de resíduos da indústria de filetagem de tilápias em rações para frangos de corte. Revista Brasileira de Zootecnia, Brasília, v. 39, n. 12, p. 2670-2675, 2010.

EYNG, C.; NUNES, R. V.; POZZA, P. C.; TSUTSUMI, C. Y.; BITTENCOURT, F.; FRANK, R.; SCHONE R. Valor nutricional da farinha de resíduos da indústria de filetagem de tilápias. In: ZOOTEC, 2009, Águas de Lindóia. Anais... São Paulo: Zootec, 2009. CD-ROM.

GAYA, L. G.; FERRAZ, J. B. S.; REZENDE, F. M.; MATTOS, E. C.; ELER, J. P.; MICHELAN FILHO, T. Heritability and genetic correlations estimates for performance and carcass and body composition traits in a male broiler line. Poultry Science, Savoy, v. 85, n. 5, p. 837-843, 2006.

GONZALES, E.; SARTORI, J. R. Crescimento e metabolismo muscular. In: MACARI, M.; FURLAN, R. L.; GONZALES, E. (Ed.). Fisiologia aviária aplicada a frangos de corte. Jaboticabal: FUNEP/UNESP, 2002. p. 279-297.

LEESON, S. Nutrição e qualidade de carcaça de frangos de corte. In: CONFERÊNCIA APINCO DE CIÊNCIA E TECNOLOGIA AVÍCOLA, 1995, Curitiba. Anais... Campinas: FACTA, 1995. p. 111-118.

MOREIRA, J.; MENDES, A. A.; GARCIA, E. A.; OLIVEIRA, R. P.; GARCIA, R. G.; ALMEIDA, I. C. L. Avaliação de desempenho, rendimento de carcaça e qualidade de carne do peito em frangos de linhagens de conformação versus convencionais. Revista Brasileira de Zootecnia, Brasília, v. 32, n. 6, p. 1663-1673, 2003. 
NOVELlO, D.; OST, P. R.; FONSECA, R. A.; NEUMANN, M.; FRANCO, S. G.; QUNTILIANO, D. A. Avaliação bromatológica e perfil de ácidos graxos da carne de frangos de corte alimentados com rações contendo farinha de peixe ou aveia-branca. Revista Brasileira de Zootecnia, Brasília, v. 37, n. 9, p. 16601668, 2008.

NOVELLO, D.; OST, P. R.; NEUMANN, M.; FONSECA, R. A.; FRANCO, S. G.; QUINTILIANO, D. A. Avaliação zootécnica e qualidade da carcaça de frangos de corte alimentados com rações contendo farinha de peixe ou aveia branca. Ciência Rural, Santa Maria, v. 37, n. 5, p. 1430-1435, set./out. 2007.

OLIVEIRA NETO, A. R.; OLIVEIRA, R. F. M.; DONZELE, J. L.; ROSTAGNO, H. S.; FERREIRA, R. A.; CARMO, H. M. Níveis de energia metabolizável para frangos de corte no período de 22 a 42 dias de idade mantidos em ambiente termoneutro. Revista Brasileira de Zootecnia, Brasília, v. 29, n. 4, p. 1132-1140, 2000.

PONCE, L. E.; GERNAT, A. G. The effect of using different levels of tilapia by-product meal in broiler diets. Poultry Science, Savoy, v. 81, n. 7, p. 1045-1049, 2002.

ROSTAGNO, H. S.; ALBINO, L. F. T.; DONZELE, J. L.; GOMES, P. C.; OLIVEIRA, R. F.; LOPES, D. C.; FERREIRA, A. S.; BARRETO, S. L. T. Tabelas brasileiras para aves e suínos: composição de alimentos e exigências nutricionais. Viçosa: UFV, Departamento de Zootecnia, 2005. 186 p.

STATISTIC ANALYSIS SYSTEM - SAS. Painless Windows, a handbook for SAS users. 2. ed. Guelph: Jodie Gilmore. 2001. 61 p.

SCHERER, C.; FURLAN, A. C.; MARTINS, E. N.; SCAPINELLO, C.; TON, A. P. S. Exigência de energia metabolizável de codornas de corte no período de 1 a 14 dias de idade. Revista Brasileira de Zootecnia, Brasília, v. 40, n. 11, p. 2496-2501, 2011.
SI, J.; FRITTS, C. A.; BURNHAM, D. J.; WALDROUP, P. W. Relationship of dietary lysine level to the concentration of all essential amino acids in broiler diets. Poultry Science, Savoy, v. 80, n. 10, p. 1472-1479, 2001.

SILVA, C. R.; NOBRE JUNIOR, F. M.; NERY, L. R.; BERNARDINO, V.; BRITO, C. O.; ROSTAGNO, H. $\mathrm{S}$. Composição química e valores energéticos de alguns alimentos de origem animal usados na alimentação de frangos de corte. In: CONFERÊNCIA DE CIÊNCIA E TECNOLOGIA AVÍCOLAS, 2006, Santos. Anais... Santos: APINCO, 2006, p. 123.

SILVA, D. J.; QUEIROZ, A. C. Análise de alimentos: métodos químicos e biológicos. Viçosa: UFV, 2002. 235 p.

TON, A. P. S.; FURLAN, A. C.; MARTINS, E. N.; TOLEDO, J. B.; SCHERER, C.; CONTI, A. C. M. Exigências de lisina digestível e de energia metabolizável para codornas de corte em crescimento. Revista Brasileira de Zootecnia, Brasília, v. 40, n. 3, p. 593-601, 2011.

TRINDADE NETO, M. A.; TAKEARA, P.; TOLEDO, A. L.; KOBASHIGAWA, E.; ALBUQUERQUE, R.; ARAÚJO, L. F. Níveis de lisina digestível para frangos de corte machos no período de 37 a 49 dias de idade. Revista Brasileira de Zootecnia, Brasília, v. 38, n. 3, p. 508-514, 2009.

TUCCI, F. M.; LAURENTIZ, A. C.; SANTOS, E. A.; RABELlO, C. B.; LONGO, F. A.; SAKOMURA, N. R. Determinação da composição química e dos valores energéticos de alguns alimentos para aves. Acta Scientiarum Animal Sciences, Maringá, v. 25, n. 1, p. 8589, 2003.

WANG, X.; PARSONS, C. M. Dietary formulation with meat and bone meal on a total versus a digestible or bioavailable amino acid basis. Poultry Science, Savoy, v. 77, n. 7, p. 1010-1015, 1998. 